\title{
Analysis of Exhaust Gas Visibility in Iron Ore Sintering Plant
}

\author{
Shunji KASAMA, ${ }^{1)}$ Hisatsugu KITAGUCHI, ${ }^{2)}$ Yuichi YAMAMURA, ${ }^{3)}$ Kazuomi WATANABE $^{3)}$ and \\ Akifumi UMEZU4) \\ 1) Environmental and Process Technology Center, Nippon Steel Corp., Shintomi 20-1, Futtsu, Chiba $293-8511$ Japan. \\ 2) Advanced Research Technology Center, Nippon Steel Corp., Shintomi 20-1, Futtsu, Chiba 293-8511 Japan. \\ 3) Oita Works, Nippon Steel Corp., 1 Oaza-Nishinosu, Oita 870-0992 Japan. \\ 4) Nagoya Works, Nippon Steel Corp., 5-3, Tokaimachi, Tokai, Aichi 476-8686 Japan.
}

(Received on March 14, 2006; accepted on April 6, 2006; originally published in Tetsu-to-Hagané, Vol. 91, 2005, No. 10, pp. 757-762)

\begin{abstract}
Visible smoke of exhaust gas from iron ore sintering plants spoil the scenery around the works. In this paper, the mechanism of formation of visible smoke is discussed by detailed analysis of the exhaust gas components and dust in the Oita No. 1 sintering plant. The main substance of visible smoke was mist condensing in the air during the cooling of exhaust gas that contained $0.1 \mathrm{ppm}$ of sulfuric acid $\left(\mathrm{SO}_{3}\right)$. Sulfuric acid is considered to raise the dew point and so facilitate mist condensation, and to lower the vaporization of visible mist containing sulfuric acid solution. Dust in the exhaust gas is also considered to act as nucleation sites for mist condensation. This proposed mechanism was confirmed by the test remixing $\mathrm{SO}_{x}$-rich gas with desulfurization gas in the Nagoya No. 3 sintering plant. Long trails of visible smoke were observed by remixing $\mathrm{SO}_{x}$-rich gas with exhaust gas. In conclusion, in order to make exhaust gas invisible, it is not sufficient to enhance the dust collecting system: desulfurization equipment in the sintering plant is necessary.
\end{abstract}

KEY WORDS: iron ore sintering; sulfur oxides; $\mathrm{KCl}$; dust; plant measurement; exhaust gas.

\section{Introduction}

The iron ore sintering process in steel works is a process with potential impact on the environment, particularly on the atmosphere, and much effort has been made to reduce the impact. To remove dust from the exhaust gases, high-efficiency electric precipitators such as electric precipitators of the rotary collecting electrode type ${ }^{1)}$ have been developed and introduced to reduce exhaust emissions from such works. For desulfurization and denitration, dry-type desulfurizing and denitrifying systems utilizing activated coke adsorption $^{2)}$ are now used in addition to the conventional wet-type. Concerning dioxin emissions from sintering plants, in response to the enforcement of the Special Law for Countermeasures against Dioxins in January 2000, much basic research has been done to clarify the behavior of dioxins in the sintering process as well as to develop technology to control emissions in the process.

The colors of exhaust gas smoke from sintering plants often attract criticism, although not in connection with environmental regulations. The smokestacks of sintering plants are not only high and conspicuous, but also the smoke of exhaust gases from the stacks of usual sintering plants typically tends to trail longer than from the stacks of other types of plants. The effects of the conspicuous smoke on the scenery around steel works and on the psychology of people undeniably adversely affect the impression of steel works, even if such effects cannot be measured.

Since the color of exhaust gases has no direct impact on the environment but relates to people's feelings, few studies have been done in this area. Saito et al. ${ }^{4}$ inferred the visible range of smoke from the relation between dust particle diameter and concentration, based on Mie's theory of light scattering, and explained the effect of sulfuric acid mist on the color of smoke from heavy-oil boilers. The idea of their study is interesting as it tries to scientifically interpret the color of exhaust gas smoke, but the appropriateness of the inferred range has not been fully verified. Careful verification of the inference relative to sintering exhaust gases that have different gas and dust properties is therefore necessary.

The authors have analyzed exhaust gas components and dust from a sintering plant in detail, focusing on the color of the exhaust gas smoke on which few studies have been made. This paper reports on the study and discusses the substances that cause visible smoke and technologies to control it.

\section{State of Visible Smoke of Sintering Exhaust Gases and Conventional Findings}

\subsection{Relationship between Amount of Dust in Exhaust Gases and Visible Smoke}

Prior to analyzing the causes of visible gas, the authors examined the relation between the color of smoke and the amount of dust determined by a light scattering type of densitometer. Figure 1 shows the results. The colors of the smoke, shown along the ordinate axis, were observed for 


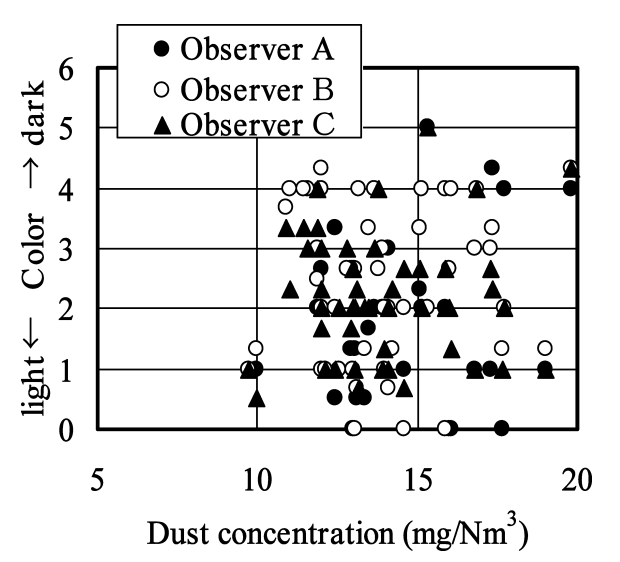

Fig. 1. Relation between the visual impression and dust concentration of exhaust gases from the sintering plants.

three months by three examiners at certain fixed points and are expressed in sensory indices representing the examiners' impressions of the density, hue (conspicuity against the background sky color) and length of the smoke on a scale of 0 to 5 . The results show that the concentration of the visible smoke scarcely depends on the concentration of the dust in the exhaust gases. All steel works have worked hard to improve dust removing performance and reduce dust concentration, and have replaced existing dust precipitators with improved ones whenever the dust precipitators have been renewed, but the results show that these efforts have had little effect on visible smoke.

\subsection{Conventional Findings on Causative Mechanism of Visible Smoke}

Fine particles present in exhaust gases render the gases visible in the form of smoke by the scattering of light. Many studies on fine particles that can cause visible smoke have been conducted in the field of boiler exhaust treatment, and water vapor and sulfuric acid mist $\left(\mathrm{SO}_{3}\right.$ mist) have been identified as the main types. ${ }^{4)}$ The causes of white smoke in the wet-type desulfurization of boiler exhaust gases are the formation of sulfuric acid mist by contact with treating water and the formation of ammonium hydrogen sulfite by reaction with $\mathrm{NH}_{3}$, and wet-type electric precipitators are used as preventive measures in later stage of the treating processes. ${ }^{4,5)}$

In sintering processes, on the other hand, it is thought that $\mathrm{SO}_{3}$ is scarcely produced even though sintering exhaust gases contain large amounts of $\mathrm{SO}_{2}$. For this reason, steel is usually widely used for exhaust gas piping, while stainless steel is rarely used. Moreover, in the case of general types of sintering machines, exhaust gases are as hot as 120 to $150^{\circ} \mathrm{C}$ and contain no ammonia, so the presence of fine particles, which can cause smoke in boiler exhaust gases, is improbable.

Conceivable fine particles that may be contained in exhaust gases from sintering machines are iron ore dust and alkaline fine particles, but few studies have been reported on the analysis of clean exhaust gases screened with electric precipitators. To determine which substances cause visible smoke in exhaust gases from a sintering plant following commercial plant tests have been carried out.

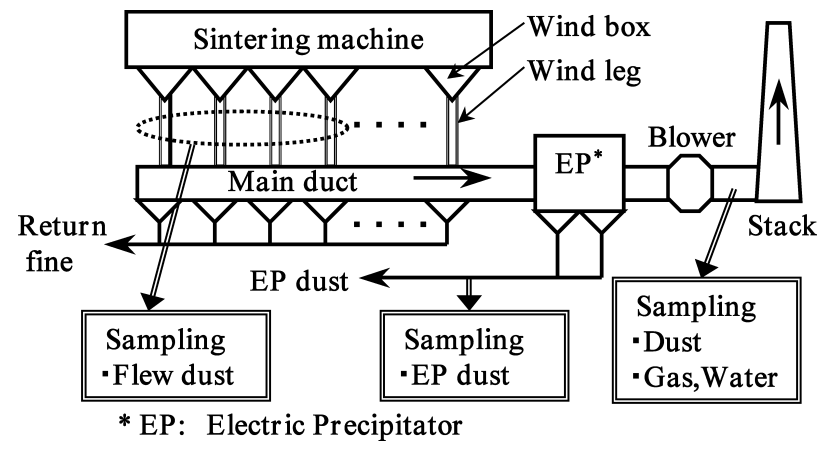

Fig. 2. Sampling positions for dusts, gas and water of exhaust gases in the sintering plant.

\section{Testing Method}

\subsection{Dust Sampling and Analyzing Methods}

In the No. 1 Sintering Plant at the Oita Works of Nippon Steel Corporation, three different type of dusts were sampled as follows;. flying dust at main wind legs, dust collected by electric precipitators, and flying dust at the entrance to the smokestack. Figure 2 shows a schematic gas flow in the exhaust system. For the dust at the wind legs, sampling holes were made in wind legs No. 9 and No. 13 to No. 21 . Flying dusts were sampled by suction under a constant gas velocity at each wind box. For the exhaust gases at the entrance to the smokestack where dust concentration was very low, the suction and filtration for sampling this dust was continued for about one week until the collected amount was sufficient for analysis.

Each sampled dust was measured with a laser particlesize meter for particle size distribution and was chemically analyzed for main components. The flying dust sampled at the entrance to the smokestack was analyzed with a scanning electron microscope (SEM) to examine the structure in detail.

\subsection{Exhaust Gas and Condensate Water Analyzing Methods}

The concentrations of $\mathrm{CO}, \mathrm{CO}_{2}, \mathrm{O}_{2}$, water, $\mathrm{SO}_{x}, \mathrm{NO}_{x}$ and dioxins were measured as general components of exhaust gases at the entrance to the smokestack. To verify the presence of sulfuric acid mist, the $\mathrm{SO}_{3}$ concentration in the exhaust gases was also measured. The $\mathrm{SO}_{3}$ concentration was quantitatively determined by neutralizing titration for sulfuric acid, condensed between the spiral tubes. ${ }^{6}$ )

To estimate the components of the water vapor formed by cooling with the atmospheric air at the outlet of the smokestack, the exhaust gases was cooled to sample the condensate water at the inlet to the smokestack to around atmospheric temperature. The alkalis, sulfate and nitrate contents in the condensate water were also determined.

\section{Results of Analysis}

\subsection{Properties of Dust in Exhaust Gases}

Figure 3 shows the particle size distribution of dust collected by the electric precipitator and sampled at the inlet to the smokestack. The collected dust was fine dust of approximately $40 \mu \mathrm{m}$ median size. The dust that was not collected by the precipitator but passed to the smokestack was very 


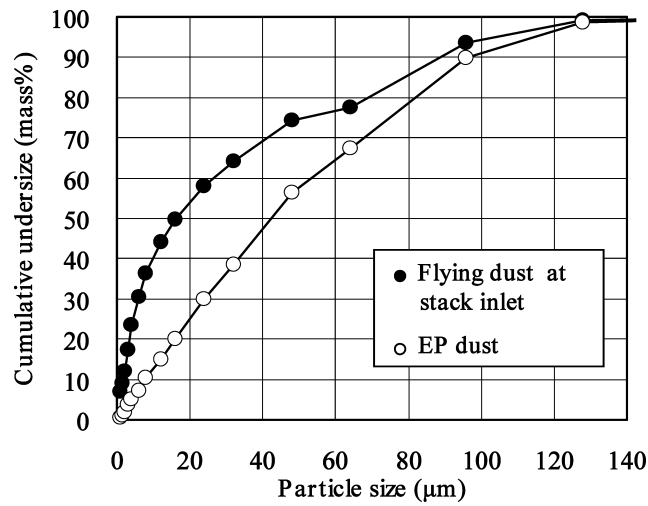

Fig. 3. Size distribution of dusts collected by electric precipitator and flying dusts collected at the stack inlet.
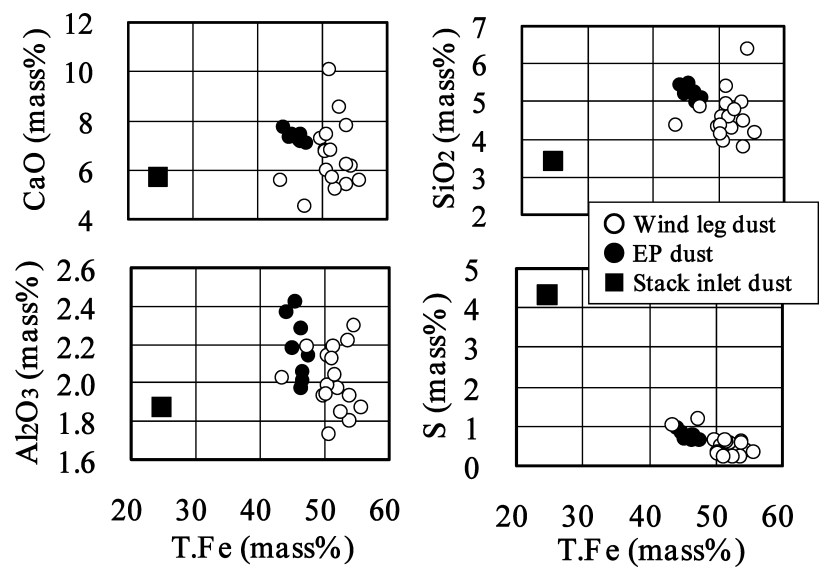

Fig. 4. Concentrations of main components of dusts collected from wind legs, electric precipitator and the stack inlet.

fine dust, with $40 \%$ smaller than $10 \mu \mathrm{m}$.

Figures $\mathbf{4}$ and $\mathbf{5}$ show the chemical composition of the sampled dust. In these figures, the abscissa axis represents Fe which indicates the amount of dust originated from iron ore, and the ordinate axis indicates the other components. The amount of $\mathrm{Fe}$ in the dust decreased as the dust flowed downstream from the wind leg through the electric precipitator to the smokestack of the exhaust gas system. This was probably because the iron ore dust, which has high specific gravity, was selectively caught by the dust catcher at the bottom of the main duct and by the electric precipitator. The amounts of $\mathrm{CaO}, \mathrm{SiO}_{2}$ and $\mathrm{Al}_{2} \mathrm{O}_{3}$, which become components of slag, were somewhat large in the electric precipitator dust and were smaller in the smokestack entrance dust. The amounts of $\mathrm{S}, \mathrm{K}, \mathrm{Na}$ and $\mathrm{Cl}$ in the dust increased as the dust flowed through the lower reaches of the exhaust gas system. The dust taken at the entrance to the smokestack, in particular, showed a peculiar component composition, with more than $25 \%$ being $\mathrm{Cl}$ and $\mathrm{K}$ alone. Assuming that the $\mathrm{K}$ and $\mathrm{Na}$ in this dust are of chlorides, the theoretical amounts and actual measurements of the chlorine are plotted and compared in Fig. 6. As the two lie almost diagonally, quantitatively speaking the two are most probably in the form of chlorides.

Figure 7 shows the results of the point analysis of the main particles determined by image observation by SEM and energy dispersive X-ray spectroscope. Many fine particles mainly comprising $\mathrm{KCl}$ were observed, and also sub-
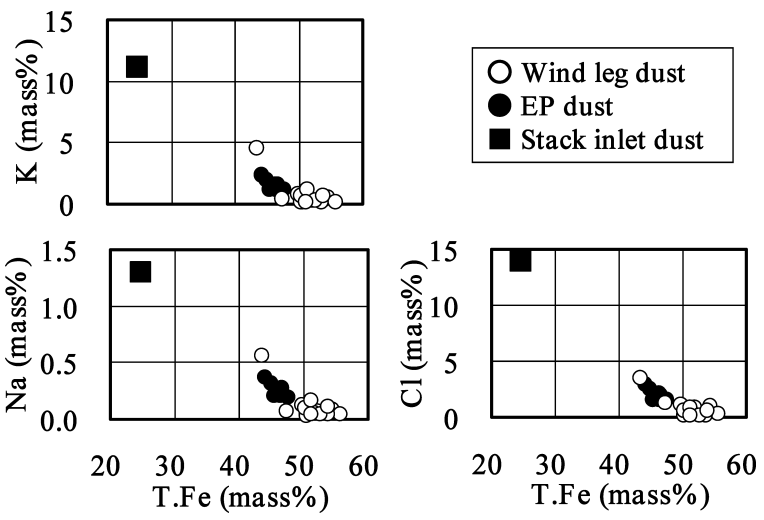

Fig. 5. Concentrations of alkalis and chlorine of dusts collected from wind legs, electric precipitator and the stack inlet.

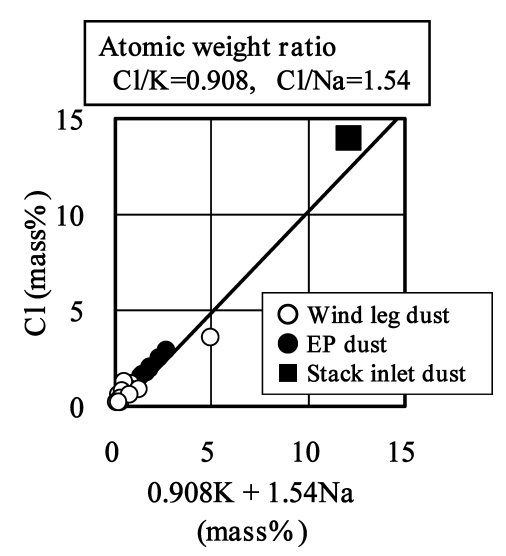

Fig. 6. Comparison between chlorine concentrations measured and concentrations calculated from alkalis.

micron $\mathrm{KCl}$ particles were seen deposited on the surfaces of iron ore dust particles of relatively large particle sizes.

\subsection{Exhaust Gas Components}

Table 1 lists the results of analyzing the smokestack entrance exhaust gases and condensed water. These results show a typical exhaust gas composition with $\mathrm{O}_{2}$ content of $14.9 \mathrm{vol} \%$ and $\mathrm{CO}_{2}$ content of $7.9 \mathrm{vol} \%$ and also show that the $\mathrm{NO}_{x}$ and $\mathrm{SO}_{x}$ contents are at standard levels. Regarding $\mathrm{SO}_{3}$, which was of particular interest in this study, its presence in the exhaust gas was verified, though at a lowest detectable level of $0.1 \mathrm{ppm}$. On the other hand, the analysis of the condensed water detected $126 \mathrm{ppm}$ of $\mathrm{SO}_{4}^{2-}$ ions, which are equivalent to $1 \mathrm{ppm}$ of $\mathrm{SO}_{3}$ in exhaust gas. This may be explained by a small amount of $\mathrm{SO}_{2}$ gas which, after dissolution into the condensate, underwent ionization to $\mathrm{SO}_{3}^{2-}$ and then oxidized to $\mathrm{SO}_{4}^{2-}$. As a consequence, the sulfuric acid concentration in the condensed water tends to be higher than the $\mathrm{SO}_{3}$ concentration in the exhaust gases.

\section{Discussion}

\subsection{Inference of Mechanism of Visible Smoke Genera- tion by Sulfuric Acid Mist}

Kawati et al. ${ }^{7}$ worked out a model for visualizing exhaust gases from wet-type cooling towers, by applying a cloud physics model for the cloud formation of visible smoke under the condition of moisture supersaturation in 


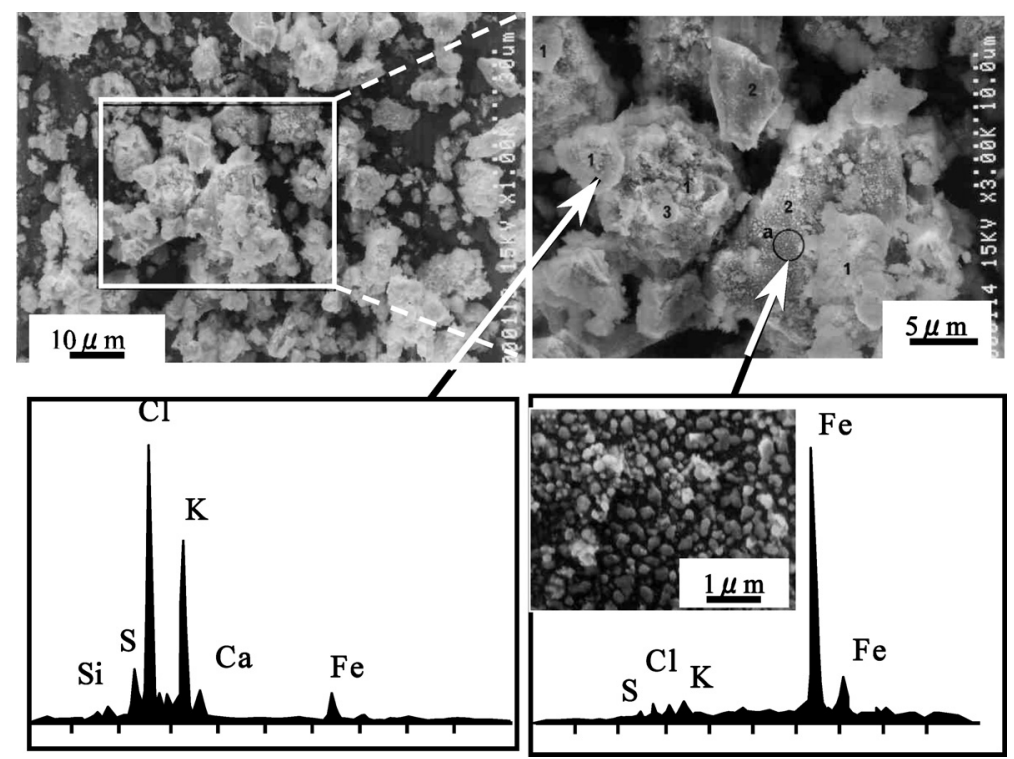

Fig. 7. Results of dust surface observation by scanning electron microscope and energy dispersive X-ray spectroscopy.

Table 1. Chemical analysis results of exhaust gas and condensed water from the exhausted gas.

\begin{tabular}{lcll}
\hline \multicolumn{2}{l}{ Exhaust gas } & \multicolumn{2}{l}{ Condensed water } \\
\hline$\cdot$ Moisture $6.9 \mathrm{vol} \%$ & & $\cdot \mathrm{Na}^{+}$ & $0.5 \mathrm{ppm}$ \\
$\cdot \mathrm{O}_{2}$ & $14.7 \mathrm{vol} \%$ & $\cdot \mathrm{K}^{+}$ & $1.1 \mathrm{ppm}$ \\
$\cdot \mathrm{CO}_{2}$ & $7.9 \mathrm{vol} \%$ & $\cdot \mathrm{NO}_{2}$ & $<0.1 \mathrm{ppm}$ \\
$\cdot \mathrm{CO}$ & $1.2 \mathrm{vol} \%$ & $\cdot \mathrm{NO}_{3}^{-}$ & $1.4 \mathrm{ppm}$ \\
$\cdot \mathrm{NOx}$ & $166 \mathrm{ppm}$ & $\cdot \mathrm{SO}_{3}{ }^{2-}$ & $1.2 \mathrm{ppm}$ \\
$\cdot \mathrm{SOx}$ & $127 \mathrm{ppm}$ & $\cdot \mathrm{SO}_{4}{ }^{--}$ & $126 \mathrm{ppm}$ \\
$\cdot \underline{\mathrm{SO}} 3$ & $0.1 \mathrm{ppm}$ & $\cdot \mathrm{NH}_{3}{ }^{+}$ & $2.3 \mathrm{ppm}$ \\
$\cdot \mathrm{DXN}$ & $39 \mathrm{ng} / \mathrm{Nm}^{3}$ & & \\
$\cdot \mathrm{FRN}$ & $39 \mathrm{ng} / \mathrm{Nm}^{3}$ & \\
$\cdot$ Dust & $6 \mathrm{mg} / \mathrm{Nm}^{3}$ & \\
\hline
\end{tabular}

gases. Like this model, the formation of visible smoke in exhaust gases from the sintering process is considered to be due to moisture supersaturation in exhaust gases. Since, however, sulfuric acid mist is present at a very small concentration of about $0.1 \mathrm{ppm}$, the rise in dew point by sulfuric acid needs to be taken into account. The following description discusses the condensation of water vapor in exhaust gases from sintering machine in terms of the dew point rise by sulfuric acid.

The phenomenon of dew point rise owing to the presence of sulfuric acid in gases containing water vapor is generally well known as "acid dew point", and many researchers have attempted to determine ${ }^{6}$ or estimate ${ }^{8)}$ the dew point. In the present research, using the practical estimation equation ${ }^{9)}$ given in Eq. (1) below, dew points at different sulfuric acid concentrations and moisture contents in exhaust gases were calculated and thus plotted in Fig. 8.

$$
\begin{aligned}
T= & 3987 /\{18.5815-\ln (760 \cdot M / 100) \\
& +8.4071 \cdot \ln (10 \cdot S / M)\}-165.3 \ldots
\end{aligned}
$$

where, $T$ : dew point $\left({ }^{\circ} \mathrm{C}\right)$

$S: \mathrm{SO}_{3}$ concentration in exhaust gases (ppm)

$M$ : moisture content in exhaust gases (vol\%)

Based on Fig. 8, let us consider the possible change in the condition when $100^{\circ} \mathrm{C}$ exhaust gases containing moisture (humidity $0.11 \mathrm{~kg}-\mathrm{H}_{2} \mathrm{O} / \mathrm{kg}$-dry air) are released to at-

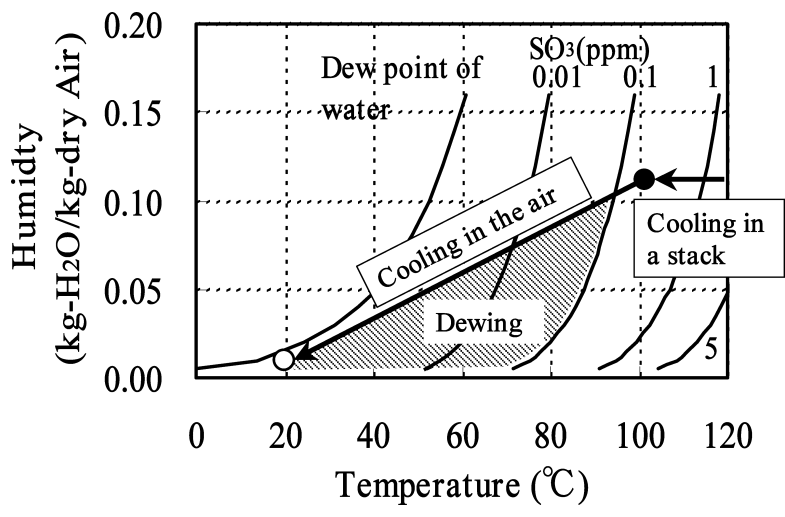

Fig. 8. Dew point curves considering the influence of sulfuric acid.

mospheric air at $20^{\circ} \mathrm{C}$. The figure suggests that if no sulfuric acid at all is contained, the exhaust gases are cooled without condensation because the cooling curve does not intersect the dew point curve. It also suggests that, if the atmospheric temperature drops or the moisture content in the exhaust gases increases, moisture condensation may result.

On the other hand, in the presence of $0.1 \mathrm{ppm}$ of $\mathrm{SO}_{3}$, the dew point rises sharply, the cooling curve may reach the dew point even at a high temperature of $95^{\circ} \mathrm{C}$, and supersaturation may ensue, so the moisture may be condensed to liquid containing sulfuric acid. In order for moisture-saturated air to be condensed into liquid drops, nucleation starting points are necessary. In the case of exhaust gases from the sintering process, they contain innumerable dust particles as shown in Fig. 7 and such dust particles may act as nuclei. According to our observation, exhaust gases from the actual sintering plant smokestack were clear in a range from the smokestack outlet up to a gas flow length of about $10 \mathrm{~m}$ and became whitish as they flowed further. They became whitish presumably because the exhausted gases were cooled in the atmosphere and underwent moisture supersaturation, nucleation, and condensation. 


\subsection{Inference of Mechanism of Visible Smoke Trails}

A phenomenon characteristic to exhaust gases from sintering plant smokestacks is a long horizontal trail of visible smoke. If the visible smoke is formed by moisture condensation, it should soon disappear as the moisture re-evaporates, but exhaust gases from sintering plants often form a long horizontal trail of smoke, extending up to several kilometers.

One of the mechanisms which may explain the long horizontal smoke trails phenomenon is the concentration of sulfuric acid in mist by evaporation. Figure 9 shows the relation between sulfuric acid concentration and vapor pressure. ${ }^{10)}$ The aqueous solution of sulfuric acid has a property of decreasing equilibrium vapor pressure with increasing sulfuric acid concentration. The Authors In view of it, w therefore inferred a mechanism, shown in Fig. 10, which explains the trailing of visible smoke as follows. The mist condensed onto the surface of dust particles after emission from a smokestack gradually re-evaporates upon contact with dry air, and so the concentration of sulfuric acid in the mist increases as moisture is removed by the evaporation. The increase in sulfuric acid concentration decreases the equilibrium vapor pressure of moisture according to Fig. 9. As the re-evaporation progresses, the equilibrium vapor pressure reaches equilibrium with the vapor pressure in the atmosphere, and the mist no longer evaporates but diffuses into the atmosphere. The particle sizes of the diffusing mist are in a range that is visible to the human eye, and thus exhaust gases from sintering plant smokestacks are observed in the form of a long horizontal trail of smoke.

In regard to the visibility of fine particles, Saito et al. ${ }^{4)}$

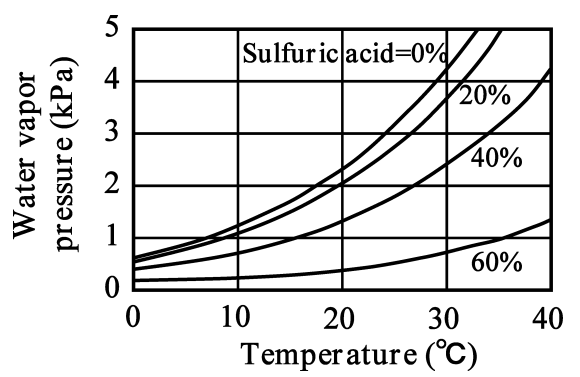

Fig. 9. Equilibrium relation between water vapor pressures and temperatures of the sulfuric acid solutions

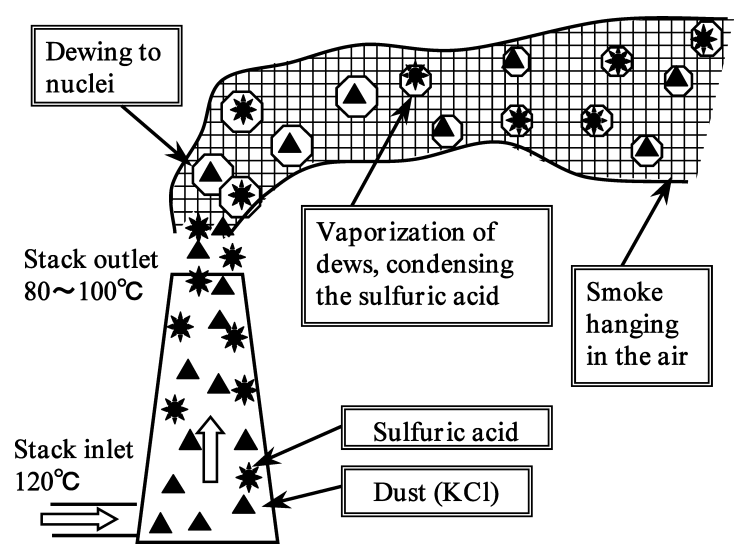

Fig. 10. Proposed mechanism to explain long visible smoke of exhaust gas in the sintering plant inferred a visibility range in terms of the concentration and diameter of fine particles, based on Mie's theory of light scattering, and compared their theoretical results with the results of actual investigations. According to their findings, a mass of fine particles in a range of 0.1 to $0.2 \mu \mathrm{m}$ in particle diameter is theoretically visible under certain conditions, and the finer the particles the more the particles are visible even when the particle concentration is low. In the case of exhaust gases from sintering plants, the size of particles contained in them diminishes as the mist evaporate, making the long horizontal trail of smoke less easy to disappear.

In view of the above discussions, in order to make exhaust gases from sintering plants invisible, it is necessary to prevent the formation of sulfuric acid mist originating from $\mathrm{SO}_{3}$ and $\mathrm{SO}_{2}$ by installing exhaust gas desulfurization equipment.

\subsection{Verification of Visible Smoke Generation from Ac- tual Sintering Plant}

Figure 11 shows an exhaust gas system flow in the No. 3 Sintering Plant at Nagoya Works of Nippon Steel Corporation. The sintering plant has a dry desulfurization system of the activated coke adsorption type as shown in Fig. 12, by which $95 \%$ or more sulfur oxides and 15 to $20 \%$ of nitrogen oxides are removed through mixing contact between the exhaust gases and activated coke in an adsorption column. The $\mathrm{SO}_{x}$-rich gas adsorbed and collected by the activated coke is usually rendered harmless in a downstream magnesium hydroxylation process. Since this exhaust gas treating system was introduced in the sintering plant, the smoke color of the exhaust gases from the plant has remained clear.

When the magnesium hydroxylation equipment was repaired one time, the plant was temporarily operated with the unusual arrangement of making the $\mathrm{SO}_{x}$-rich gas flow through a bypass and returning it to the smokestack. The results of smoke color observations at that time are shown in Fig. 11. Returning the $\mathrm{SO}_{x}$-rich gas to the smokestack

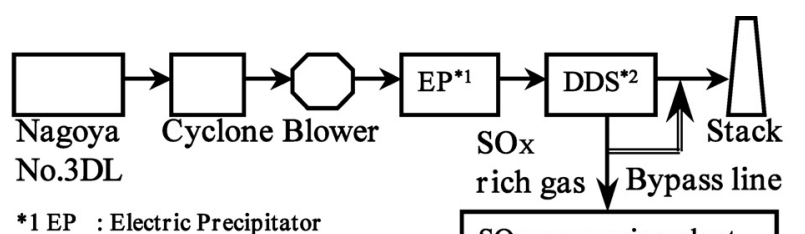

*2 DDS: Dry Desulphurization System

SOx processing plant

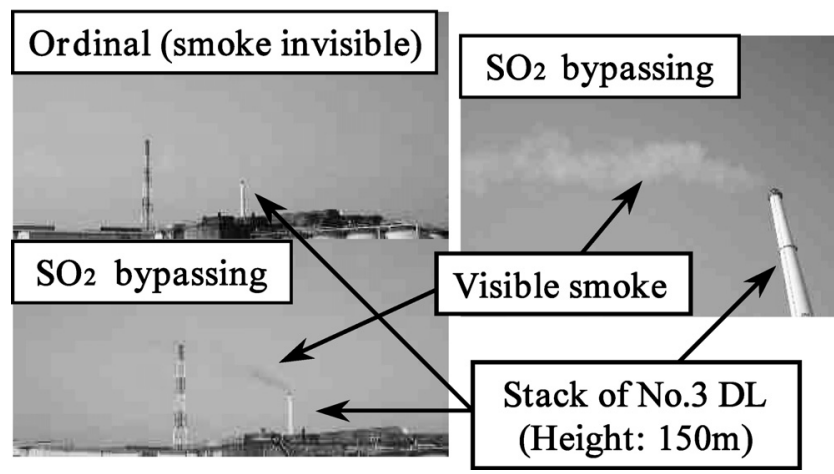

Fig. 11. Comparison of smoke colors of the exhaust gas with different gas processing. 


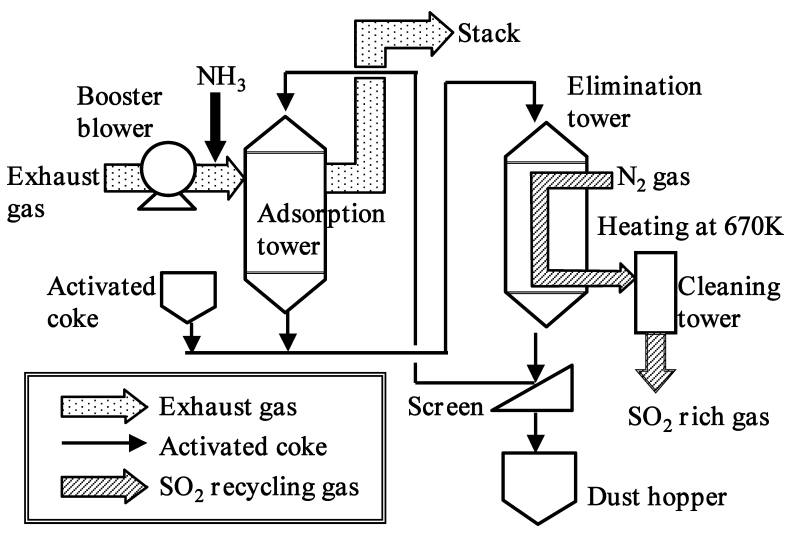

Fig. 12. Outline of dry desulphurization system.

immediately rendered the smoke visible. Table 2 shows the change in the main exhaust gas components during the unusual operation. In the unusual operation, the mixing of the $\mathrm{SO}_{x}$-rich gas increased the $\mathrm{SO}_{x}$ concentration in the smokestack exhaust gas from $7 \mathrm{ppm}$ to $168 \mathrm{ppm}$. The fact that the $\mathrm{NO}_{x}$ and the dust were at same levels as in usual operations suggests that the coloring of the smoke originated from feeding $\mathrm{SO}_{x}$, and therefore, the inferred mechanism for visible smoke generation shown in Fig. 10 is appropriate.

Considering the above discussions, the removal of fine dust by electric precipitators alone is not sufficient for completely rendering exhaust gases from sintering plants invisible; $\mathrm{SO}_{x}$ which can cause moisture condensation still needs to be removed. Since the raw materials used in the sintering process will inevitably contain sulfur, exhaust gas desulfurization equipment needs to be installed in order to minimize $\mathrm{SO}_{x}$.

As for the desulfurization equipment, the dry desulfurization equipment developed at Nagoya Works is believed to be most efficient so far and has been widely introduced both inside and outside Japan. Sintering processes in steel works have not only to meet the environmental regulations on exhaust gases but also need to develop comprehensive exhaust gas control measures from various aspects, including the problem of visible smoke reported in this paper.

\section{Conclusion}

To elucidate the cause of visible smoke formation of exhaust gases from an iron ore sintering plant, exhaust gas
Table 2. Concentration of exhaust gas components during the $\mathrm{SO}_{x}$ bypassing operation.

\begin{tabular}{lcc}
\hline & Normal operation & SOx bypassing \\
\hline - Air flow rate & $14,200 \mathrm{Nm}^{3} / \mathrm{min}$ & $14,200 \mathrm{Nm}^{3} / \mathrm{min}$ \\
- Temperature & $415 \mathrm{~K}$ & $414 \mathrm{~K}$ \\
- NOx & $144 \mathrm{ppm}$ & $133 \mathrm{ppm}$ \\
- SOx & $7 \mathrm{ppm}$ & $168 \mathrm{ppm}$ \\
- Dust & $10 \mathrm{mg} / \mathrm{Nm}^{3}$ & $10 \mathrm{mg} / \mathrm{Nm}^{3}$ \\
\hline
\end{tabular}

components and dust in the exhaust gases were closely analyzed, and the following findings were obtained.

(1) The dust that passed through the electric precipitator is fine particles $40 \%$ of which are $10 \mu \mathrm{m}$ or less in particle size and mostly comprise iron ore powder and submicron $\mathrm{KCl}$ particles.

(2) A very small amount of $\mathrm{SO}_{3}$ at a concentration of about $0.1 \mathrm{ppm}$ is present in the exhaust gases from the sintering plant, and the rise in dew point owing to the $\mathrm{SO}_{3}$ probably induces the formation of mist and visible smoke when the gases are cooled. The phenomenon of a long horizontal trail of smoke, which is characteristic of exhaust gases from sintering plants, is considered to be due to the effect of evaporation restraint by sulfuric acid in the mist.

(3) The removal of dust alone by electric precipitators is not sufficient for preventing the formation of visible smoke of exhaust gases from sintering plants; desulfurization treatment equipment, such as exhaust gas treatment equipment of the activated coke adsorption type, is essential.

\section{REFERENCES}

1) M. Baba, T. Kitamura, J. Sakuragi, K. Oyama, J. Ikenaga and M. Maki: CAMP-ISIJ, 5 (1992), 1158.

2) H. Kusunoki, S. Kabuto, A. Umezu, M. Hamada and K. Takatani: CAMP-ISIJ, 12 (2000), 807.

3) E. Kasai and T. Aono: Tetsu-to-Hagané, 87 (2001), 228.

4) Y. Saito, K. Tashiro, S. Komura, N. Tachibana, K. Matsui and K. Yada: Mitsubisi Heavy Ind. Tech. Rev., 13 (1976), 173.

5) Y. Ueda, M. Kagami, H. Fujitani and K. Tomimatsu: Mitsubishi Heavy Ind. Tech. Rev., 38 (2001), 40.

6) E. S. Lisle and J. D. Sensenbaugh: Combustion, (1965), January, 12.

7) A. Kawati, R. Oba, K. Okabayashi and T. Nonaka: Mitsubishi Heavy Ind. Tech. Rev., 36 (1999), 42.

8) P. Muller: Chem. Ing. Technol., 31 (1959), 345.

9) Private Communication.

10) Kagaku Binran Kisohen II, ed. by Chemistry Society of Japan, Maruzen, Tokyo, (1975), 745. 